\title{
Informations bibliographiques
}

\author{
Justin Daniel
}

\section{OpenEdition}

\section{Journals}

Édition électronique

URL : http://journals.openedition.org/plc/277

DOI : $10.4000 /$ plc. 277

ISSN : 2117-5209

\section{Éditeur}

L'Harmattan

\section{Édition imprimée}

Date de publication : 14 janvier 2004

Pagination : 169-171

ISBN : 2-7475-7061-4

ISSN : $1279-8657$

Référence électronique

Justin Daniel, «Informations bibliographiques », Pouvoirs dans la Caraïbe [En ligne], 14 | 2004, mis en ligne le 02 mars 2011, consulté le 22 septembre 2020. URL : http://journals.openedition.org/plc/277 DOI : https://doi.org/10.4000/plc. 277 


\title{
INFORMATIONS BIBLIOGRAPHIQUES
}

\author{
PAR JUSTIN DANIEL
}

Ramos, Efrén Rivera, The Legal Construction of Identity. The Judicial and Social Legacy of American Colonialism in Puerto Rico, Washington DC, American Psychological Association, 2001, 275 p.

Présenté dans une édition élégante, cet ouvrage analyse les relations entre Porto Rico et les Etats-Unis au cours du dernier siècle. Juriste de formation, Efrén Ramos s'efforce de mettre au jour les mécanismes par lesquels le droit a contribué à façonner une réalité sociale singulière à Porto Rico. Pour l'auteur, les normes et construits légaux déterminent les luttes pour la définition d'une identité portoricaine spécifique. Cette lutte se nourrit notamment de la tension entre la revendication du droit à la participation et des droits inhérents à la citoyenneté américaine d'une part, et l'affirmation d'une identité culturelle distincte d'autre part. En ce sens, le droit est au cœur de l'autodétermination et de l'auto-perception de nombre de Portoricains qui revendiquent une identité nationale distincte. D'une lecture facile, bien documenté tout en constituant une excellente synthèse, cet ouvrage s'adresse en particulier aux juristes et spécialistes de sciences sociales qui s'intéressent à la relation symbiotique entre droit et société.

Duany, Jorge, Puerto Rican Nation on the Move. Identities on the Island and in the United States, Chapel Hill and London, The University of North Carolina Press, 2002.

Originaire de Cuba, mais vivant depuis longtemps à Porto Rico, Jorge Duany, dont on connaît par ailleurs la qualité des publications, nous propose dans cet ouvrage une intéressante analyse de l'identité portoricaine. Les Portoricains sont, en effet, les porteurs d'une identité 
qui s'exprime avec force dans deux lieux différents : l'île et la métropole américaine. Qu'ils vivent sur l'île ou aux Etats-Unis, ou alternativement sur les deux territoires, la plupart d'entre eux imaginent Porto Rico comme une nation distincte et se perçoivent avant tout comme Portoricains alors qu'ils jouissent de la citoyenneté américaine depuis 1917. Jorge Duany s'appuie sur des données primaires jusqu'alors inexploitées pour dégager de nouvelles perspectives lui permettant d'interroger l'identité portoricaine, le nationalisme et les phénomènes migratoires. Opérant une distinction entre nationalisme politique et nationalisme culturel, il émet l'hypothèse que la «nation » portoricaine doit être appréhendée comme une sorte d'identité translocale caractérisée par de profondes continuités culturelles. Il met en particulier l'accent sur une culture très vivace partagée aussi bien sur l'île qu'aux Etats-Unis. Basé sur des données ethnographiques, l'exploitation d'archives, d'interviews, d'enquêtes et d'articles de presse, de textes littéraires sans oublier des documents personnels, ce travail constitue une intéressante contribution à la compréhension de questions qui retiennent depuis longtemps l'attention des intellectuels mais aussi du personnel politique de l'ancienne colonie espagnole.

\section{Shepherd, Verene A. et Glen L. Richards (eds.), Questioning Creole: Creolization discourses in Caribbean Culture, Kingston, Jamaica, Oxford, Ian Randle Curry, 2002, 305 p.}

Dans son œuvre majeure, The Development of Creole Society in Jamaica, Kamau Brathwaite tente de saisir l'identité " jamaïcaine » qui s'est développée aux interstices des cultures européennes et africaine. Dépassant le simple exposé du concept de société créole, il propose un modèle clair et intellectuellement engagé analysant le processus de changement culturel permettant de définir et de distinguer les sociétés créoles : la « créolisation ». On sait que ce travail pionnier a donné lieu à des controverses vigoureuses parmi les spécialistes qui ont appliqué le concept de créolisation au-delà des frontières de la Caraïbe. Ce concept $\mathrm{a}$ d'ailleurs été repris des deux côtés de l'Atlantique. L'ouvrage collectif 
dirigé par Shepherd Verene et Glen Richards, deux historiens, la première enseignant à l'Université des West Indies en Jamaïque après avoir été l'étudiante puis la collègue de Kamau Brathwaite, le second à l'Université de Cambirdge a délibérément privilégié une approche multidisciplinaire: il comporte des contributions d'historiens, de sociologues, de spécialistes de littérature. Loin de nuire à sa cohérence, ces analyses se réclamant de disciplines différentes s'enrichissent mutuellement. D'autant que les auteurs ne partagent pas tous la même conception de la créolisation. Il en résulte un ouvrage d'un intérêt incontestable et dont certaines contributions sont denses et profondes.

\section{Price, Richard et Sally, Les Marrons, Châteauneuf-le-Rouge (France), Vents d'Ailleurs, 2003.}

Voilà un petit ouvrage intéressant proposé par deux des meilleurs spécialistes des sociétés marronnes de Guyane française. Richard et Sally Price capitalisent en une remarquable synthèse plusieurs décennies d'observation de ces sociétés et nous offrent, après avoir retracé leur histoire, un tableau passionnant de leurs us et coutumes, de leurs cultures et de leurs arts. Illustré par de nombreuses photographies, l'ouvrage est écrit dans un style clair et élégant qui le rend accessible à un public large tout en reposant sur des analyses scientifiques rigoureuses. 